\title{
Tautomerism of lactones and related compounds. Mass spectrometric data and theoretical calculations *
}

\author{
Patricia E. Allegretti, M. Susana Cortizo, ${ }^{\mathrm{b}}$ Celia Guzmán, ${ }^{\mathrm{a}}$ Eduardo A. Castro, \\ and Jorge J. P. Furlong \\ ${ }^{a}$ LADECOR (UNLP), División Química Orgánica, Departamento de Química, Facultad de \\ Ciencias Exactas, Universidad Nacional de La Plata, Calle 47 y 115, (1900) La Plata, \\ Argentina \\ ${ }^{b}$ INIFTA (UNLP-CONICET), Departamento de Química, Facultad de Ciencias Exactas, \\ Universidad Nacional de La Plata, CC16 Suc.4, (1900) La Plata, Argentina \\ ${ }^{c}$ CEQUINOR (UNLP- CONICET), Departamento de Química, Facultad de Ciencias \\ Exactas, Universidad Nacional de La Plata, C.C. 962, (1900) La Plata, Argentina \\ E-mail: castro@quimica.unlp.edu.ar /jubert@arnet.com.ar
}

\section{Dedicated to Prof. Roberto A. Rossi and Prof. Edmundo Rúveda}

(received 12 Jan 03; accepted 06 Mar 03; published on the web 11 Apr 03)

\begin{abstract}
The enolization degree of lactones and esters is favoured by the oxygen-sulfur exchange in the respective functional groups. The analysis of the corresponding mass spectra has allowed unambiguous assignment of some fragments to specific tautomers and establishment of an acceptable correlation between ion abundances ratios and AM1 theoretical calculations. This supports mass spectrometry as an adequate tool to evaluate the tautomerism of neutral species.
\end{abstract}

Keywords: Tautomerism, lactones, esters, mass spectrometry, thio compounds, theoretical calculations

\section{Introduction}

There has been considerable interest in the enolisation of carbonyl compounds for many years ${ }^{\mathbf{1}}$ and excellent methods exist for the generation of simple enols of aldehydes and ketones in solution. $^{2,3}$ These enols, although thermodynamically unstable with respect to their carbonyl isomers, exist for long enough to be detected by conventional methods. On the other hand, the enol forms of simple carboxylic acids and derivatives such as esters, amides and anhydrides have not been detected in solution. The relative unstability of these enols can be attributed to resonance stabilization of the keto isomers (Equation 1). 
A theoretical study ${ }^{4}$ has calculated that the energy difference between acetic and ethene-1,1diol is $10 \mathrm{kcal} \mathrm{mol}^{-1}$ greater than that between acetaldehyde and ethenol. This suggests that enols of carboxylic acids (and their derivatives) would have much lower intrinsic stability than enols of aldehydes and ketones.

However, enols can be dramatically stabilized by the introduction of bulky groups onto the carbon $\alpha$ to the carbonyl group ${ }^{5,6}$ and in some cases the enol may then be the thermodynamically stable tautomer, ${ }^{7}$ although not kinetically. ${ }^{8}$ The pentamethylphenyl group is an effective bulky substituent and provides the necessary stability for enediols (enol form of carboxylic acids and esters) ${ }^{9}$

The chemistry of these enols, (derived from carbonyl containing compounds other than ketones, including carboxylic acids and esters) has been of some interest. ${ }^{10,11}$ It is well documented that the equilibrium in equation 1 shifts towards the enol form when $\mathrm{X}$ or/and $\mathrm{Y}$ is sulfur instead of oxygen mainly due to its higher polarizability. So that the study of the corresponding equilibria can be interesting not only for the pertinent relevance of thio compounds but also for the correlative behaviour found with their oxygenated analogues, which enols, as mentioned above, are usually undetectable.



\section{Equation 1}

Data about stability and the short life time of aldehyde and ketone enols can be found in the literature. ${ }^{12}$ In addition, for carboxylic acids, the very low relative stability of their enols is a well known fact, ${ }^{4,13}$ although some of these short-life tautomers were prepared as intermediate compounds. ${ }^{14-20}$

There are few studies about lactone tautomerism. This family of compounds exhibits great biological interest. In this sense biological activity has been assayed by carrying out studies on substituted heterocyclic rings. ${ }^{21}$ In addition, the tautomeric equilibrium of lactones has been studied and evidence of the enol tautomer occurrence has been found by ${ }^{1} \mathrm{H}$ and ${ }^{13} \mathrm{C} \mathrm{NMR}$. ${ }^{22}$

There are several reports in the literature in regard to structural elucidation of organic compounds by mass spectrometry but few publications are found for the investigation of ketoenol tautomerism. From the latter, the analysis of the mass spectra of some $\beta$-diketones and the corresponding comparison among differently substituted analogues, led to the conclusion that fragmentation is strongly influenced by the keto-enol content of these compounds. ${ }^{23}$ The interest 
in mass spectrometry as a powerful analytical technique rests not only on the current availability and ease of use of mass spectrometers but also on the coupling of these instruments to highly efficient chromatographic systems (GC or HPLC). Additionally, high sensitivity (it can handle small samples) and low cost analyses are well known features.

Tautomerism of organic compounds has been the subject of numerous theoretical studies by the use of several physical and quantum-mechanical approaches. The results of AM1 calculations for tautomerization energies are satisfactory and they exhibit a good correlation with the experimental data ${ }^{24}$ so that its use is recommended, in particular for high molecular compounds. ${ }^{25}$

Ab-initio calculations provide a reasonable correlation for the tautomerization energy estimation. ${ }^{26-29}$ However these calculations are expensive and hard to apply to most of the molecules of real interest, particularly in the biochemical field. Alternatively it is possible to use semiempirical calculations assuming errors of some $\mathrm{kcal} / \mathrm{mol}$ for the tautomerization energy values. $^{30}$

In our laboratory studies on the tautomeric equilibrium of diverse families of compounds have been carried out and, so far, mass spectrometry and semiempirical calculations (AM1) have proved to constitute powerful tools for prediction of fast equilibrium occurrence. ${ }^{31-37}$ This methodology approach has been used in this work to study the tautomerism of selected lactones and esters and their thio analogues.

\section{Experimental Section}

Synthesis of thiolactones. The non-commercially available compounds were synthesized according to literature procedures. ${ }^{38}$ The resulting thio compounds where separated by gas chromatography and identified by mass spectrometry. For lactones, three thio derivatives were observed.

Gas chromatography-mass spectrometry. These determinations were done by injection of methanol solutions ( $1 \mu \mathrm{l})$ in an HP 5890 Series II Plus chromatograph coupled to an HP 5972 A mass spectrometric detector under the following conditions:

Column : HP5-MS, 30m x 0.25 mm x $5 \mu \mathrm{m}$.

Carrier gas: helium.

Injector temperature $200^{\circ} \mathrm{C}$.

Oven temperature $80^{\circ} \mathrm{C}, 10^{\circ} \mathrm{C} / \mathrm{min}, 200^{\circ} \mathrm{C}$.

Interface temperature $300^{\circ} \mathrm{C}$.

Ion source $185^{\circ} \mathrm{C}$.

The pressure in the mass spectrometer, $10^{-5}$ torr precludes ion-molecule reactions.

Electron energy: $70 \mathrm{eV}$.

Computational procedure. AM1 calculations were performed using the standard HyperChem ${ }^{\circledR}$ package. $^{39}$ Since we resorted to heat of formation values in order to rationalize experimental 
findings and the AM1 technique has been especially parameterized to reproduce this sort of experimental data, we deem this choice is a sensible one for the molecular set under study.

\section{Results and Discussion}

\section{Gas chromatography-mass spectrometry}

Tables 1 and 2 show the most relevant mass spectral data for selected lactones, thiolactones, esters and thioesters. For lactones the loss of $\mathrm{XH}$ from the molecular ions can be assigned to the enol form and the loss of $(\mathrm{M}-\mathrm{CX})^{+}$or $\left(\mathrm{M}-\mathrm{CX}_{2}\right)^{+} \cdot$ to the keto form.

Table 1. Relevant mass spectral data for selected lactones and thiolactones ${ }^{\mathrm{a}}$

\begin{tabular}{|c|c|c|c|c|}
\hline Compound & $\mathrm{M}^{+}$ & $(\mathrm{M}-\mathrm{XH})^{+}$ & $(\mathrm{M}-\mathrm{CX})^{+}$ & $(\mathrm{M}-\mathrm{CX} 2)^{+}$ \\
\hline & 186.3 & - & - & 376.4 \\
\hline & 780.0 & - & 11.6 & - \\
\hline & 430.5 & 13.7 & 15.5 & - \\
\hline & 331.1 & 48.4 & 14.5 & - \\
\hline & 233.3 & 0.3 & - & 249.8 \\
\hline & 432.5 & 0.4 & - & - \\
\hline & 370.5 & 24.6 & 12.8 & - \\
\hline & 218.8 & 58.6 & 8.8 & 5.5 \\
\hline
\end{tabular}

a The reported figures were calculated according to the following ratio: (ion abundance) x 1000/ (total ionic abundance).

The mass spectral data show an evident enol percentage increase for thio derivatives which is magnified by a second sulfur atom. This might be in part explained by the mesomeric stabilization and the better ability of sulfur, with respect to oxygen, to accommodate a positive charge (Scheme 1). 




\section{Scheme 1}

The results for lactones are also interesting in regard to their ring size. Seven-member rings seem to better stabilize the enol form probably due to a higher decrease of strain energyed in the unsaturated heterocycle. Although the differences are more significant among these compounds, the oxygenated lactones show the same behaviour.

Table 2. Relevant mass spectral data for selected esters and thioesters ${ }^{\mathrm{a}}$

\begin{tabular}{lllll}
\hline \multicolumn{1}{c}{ Compound } & \multicolumn{1}{c}{$\mathrm{M}^{+}$} & \multicolumn{1}{c}{$(\mathrm{M}-\mathrm{XH})^{+}$} & \multicolumn{1}{c}{$(\mathrm{M}-\mathrm{R})^{+}$} & ${\text {(McLafferty })^{+}}^{c}$ \\
\hline $\mathrm{CH}_{3} \mathrm{CH}_{2} \mathrm{CH}_{2} \mathrm{COOCH}_{3}$ & 6.9 & - & 43.1 & $184.9(\mathrm{M}-28)^{+}$ \\
$\mathrm{CH}_{3} \mathrm{CH}_{2} \mathrm{CH}_{2} \mathrm{CSSCH}_{3}$ & 113.0 & 1.1 & 39.2 & $10.3(\mathrm{M}-28)^{+}$ \\
$\mathrm{CH}_{3} \mathrm{CH}_{2} \mathrm{COOCH}_{2} \mathrm{CH}=\mathrm{CH}_{2}$ & 0.5 & - & 3.2 & $-{ }^{b}$ \\
$\mathrm{CH}_{3} \mathrm{CH}_{2} \mathrm{CSSCH}_{2} \mathrm{CH}=\mathrm{CH}_{2}$ & 58.4 & 9.8 & - & $-{ }^{\mathrm{b}}$ \\
\hline
\end{tabular}

a The reported figures (mass spectra from Nist'98 mass spectral database) were calculated according to the following ratio (ion abundance) x 1000/ (total ion abundance).

${ }^{\mathrm{b}}$ Not possible or neglectable due to allylic hydrogen involvement.

Open chain compounds were also considered (esters and thioesters, Table 2) and their mass spectra analyzed. The SH loss can be assigned to the enol form and, both the fragment arising from the radical loss of the alkyl moiety next to the carbonyl or thiocarbonyl groups and the McLafferty rearrangement fragment, whenever possible, can be considered as coming from the keto form.

As expected, there is a higher increase of the enol form for thio compounds. The assignment of the McLafferty rearrangement for methyl butanoate and its thio derivative is justified by the absence of the fragments $(\mathrm{M}-18)^{+} \cdot$ and $(\mathrm{M}-34)^{+}$. (Scheme 2), which should be observed in the mass spectra in case of occurrence of the enol form. 




\section{Scheme 2}

Table 3 shows the AM1 semiempirical calculations of the compounds selected for this study.

Table 3. Keto-enol heats of formation difference ( $\mathrm{kcal} \mathrm{mol}^{-1}$ ) by AM1 calculations

\begin{tabular}{|c|c|c|}
\hline Compound & Neutral molecule & Radical cation \\
\hline & 22.86 & -29.98 \\
\hline & 12.87 & -13.37 \\
\hline & 5.02 & -32.98 \\
\hline & 1.97 & 0.41 \\
\hline & 23.06 & -34.78 \\
\hline & 9.09 & -12.42 \\
\hline & -1.68 & -8.63 \\
\hline & -1.91 & -0.71 \\
\hline $\mathrm{CH}_{3} \mathrm{CH}_{2} \mathrm{CH}_{2} \mathrm{COOCH}_{3}$ & 23.98 & $2.5 \times 10^{-3}$ \\
\hline $\mathrm{CH}_{3} \mathrm{CH}_{2} \mathrm{CH}_{2} \mathrm{CSSCH}_{3}$ & 1.98 & -1.83 \\
\hline $\mathrm{CH}_{3} \mathrm{CH}_{2} \mathrm{COOCH}_{2} \mathrm{CH}=\mathrm{CH}_{2}$ & 24.36 & -16.04 \\
\hline $\mathrm{CH}_{3} \mathrm{CH}_{2} \mathrm{CSSCH}_{2} \mathrm{CH}=\mathrm{CH}_{2}$ & 2.10 & -0.84 \\
\hline
\end{tabular}

The reported keto-enol heats of formation differences for the neutral molecule and the corresponding radical cation indicate:

A tendency correlation with the mass spectral data is only obtained taking into account the calculated results for the neutral molecules. No tendency is observed when considering the molecular orbital calculations for the radical cations. This finding assigns a minimum impact on the experimental results by the occurrence (if any) of tautomerization between ionized species (radical cations). 
The lower energy requirement for the enol formation for the thio compounds, which decreases even more for dithio compounds, is also reflected by the theoretical calculation. Besides, the calculated energy decrease is somehow lower for lactones respect to esters as also observed by mass spectrometry.

\section{Conclusions}

The findings reported in this work are consistent with an important occurrence of the enol form for thiocarbonyl compounds which correlate adequately with the oxygenated analogues. Both mass spectral and theoretical calculations can be used as suitable predictive tools in respect to the ease of enolization of selected compounds.

\section{References}

1. House, H. O. Modern Synthetic Reactions, 2nd Edn.; Benjamin: Menlo Park, California 1972.

2. Chiang, Y.; Kresge, A. J.; Capponi, M.; Wirz, J. Helv. Chim. Acta 1986, 69, 1137, 1331.

3. Capon, B.; Zucco, C. J. Am. Chem. Soc. 1982, 104, 7567.

4. Hegarty, A. F.; Ngiyen, M. T. J. Am. Chem. Soc. 1984, 106, 1552.

5. Rappaport, Z.; Biali, S. J. Am. Chem. Soc. 1984, 106, 477.

6. Rappaport, Z.; Biali, S. J. Am. Chem. Soc. 1985, 107, 1701.

7. Miller, A. R. J. Org. Chem. 1976, 41, 3599.

8. Mukhopadhyaya, J. K.; Sklenák, S.; Rappoport, Z. J. Am. Chem. Soc. 2000, 122, 1325.

9. O’Neill, P.; Hegarty, A. F. J. Chem. Soc., Chem. Commun. 1987, 477.

10. Chiang, Y.; Kresge, A. J.; Pruszynski, P.; Schepp, N. R.; Wirz, J. Angew. Chem., Int. Ed. 1990, 29, 792.

11. Graham, A.; Williams, D. L. H. J. Chem. Soc., Chem. Commun. 1991, 407.

12. The Chemistry of Enols; Rappoport Z., Ed.; Wiley: Chichester, 1990.

13. Kresge A. J. Chem. Soc. Rev.1996, 25, 275.

14. Kelly, J. G.; Relihan, C. M. J. Chem. Soc., Perkin Trans 2 1997, 1175.

15. Keppler, B. K.; Nuber, B. Angew. Chem., Int. Ed. 1995, 34, 1103.

16. Andraos, J.; Chiang, Y.; Kresge, A. J.; Pojarlieff, J. G.; Schepp, N. P.; Wirz, J. J. Am. Chem. Soc. 1994, 116, 73.

17. Chiang, Y.; Jefferson, E. A.; Kresge, A. J.; Popik, V. V.; Kie, R. Q. J. Phys. Org. Chem. 1998, 11, 610.

18. Wagner, B. D.; Arnold, B. R.; Brown, G. S.; Luztyk, J. J. Am. Chem. Soc. 1998, 120, 1827.

19. Allen, B.; Hegraty, A. F.; O`Neill, P. J. Chem. Soc., Perkin Trans 2 1997, 2733.

20. Frey, J.; Rappoport, Z.; J. Am. Chem. Soc. 1996, 118, 3994. 
21. Cannay, D. J.; Lu, H-F; McKeon, A. C.; Ion, K. W.; Xu, K.; Holland, K.; Rothman, S. M.; Ferrendelli, J. A.; Covey, D. F. Bioorg. Med. Chem. 1998, 6, 43.

22. Traven, V.; Negrebetsky, V.; Vadim, V.; Vorobjera, L.; Carberry, E. A. Can. J. Chem. 1997, 55, 377.

23. Zamir, L.; Jensen, B. S.; and Larsen E. Org. Mass Spectrom. 1969, 2, 49.

24. Sygula, A.; Buda, A. J. Mol. Struct., THEOCHEM 1985, 121, 133.

25. Sygula, A. J. Chem. Res., Synop 1989, 2, 56.

26. Schlege, H. B.; Gund, P.; Fluder, E. M.; J. Am. Chem. Soc. 1982, 104, 5347.

27. Scanlan, M. J.; Hillier, I. H.; Davies, R. H. J. Chem. Soc., Chem. Commun. 1982, 685.

28. Scanlan, M. J.; Hillier, I. H.; MacDowell, A. A. J. Am. Chem. Soc. 1983, 105, 3568.

29. Cieplak, P.; Bash, P.; Singh, U. C.; Kollman, P. A.; J. Am. Chem. Soc. 1987, 109, 6283.

30. Berndt, M.; Kwiatkowski, J. S.; Budzinki, J.; Lesyng, B.; Pohorille, A. Int. J. Quantum Chem. 1979, 16, 1141.

31. Allegretti, P. E.; Milazzo, C. B.; Furlong, J. J. P. Atual. Fis. Quim. Org. 1998, 356.

32. Allegretti, P. E.; Labadie, G. R.; González Sierra, M.; Furlong, J. J. P. Afinidad LVII, 2000, 485.

33. Allegretti, P. E.; Castro, E. A.; Furlong, J. J. P. J. Mol. Struct. THEOCHEM 2000, 499, 121.

34. Allegretti, P. E.; Gavernet, L.; Castro, E. A.; Furlong, J. J. P. J. Mol. Struct. THEOCHEM 2000, 532, 139.

35. Allegretti, P. E.; Schiavoni, M. M.; Di Loreto, H.; Furlong, J. J. P.; Della Védova, C. O. J. Mol. Struct. 2001, 560, 327.

36. Allegretti, P. E.; Cánepa, A. S.; Bravo, R. D.; Castro, E. A.; Furlong, J. J. P. Asian J. Spectr. 2000, 4, 133.

37. Allegretti, P. E.; Gavernet, L.; Castro, E. A.; Furlong, J. J. P. Asian J. Spectr. 2001, 5, 63.

38. Scheibye, S.; Kristensen, J.; Lawesson, S. O. Tetrahedron 1979, 35, 1339.

39. HyperChem ${ }^{\circledR} 6.03$ for Windows Molecular Modeling System, Hypercube, Inc., Gainesville, Florida, 2000. 